\title{
Increased Phospholipase A2 Activity and Inflammatory Response But Decreased Nerve Growth Factor Expression in the Olfactory Bulbectomized Rat Model of Depression: Effects of Chronic Ethyl-Eicosapentaenoate Treatment
}

\author{
Cai Song, ${ }^{1,2}$ Xiang Yang Zhang, ${ }^{3}$ and Mehar Manku ${ }^{4}$ \\ ${ }^{1}$ Department of Biomedical Sciences, Atlantic Veterinary College, University of Prince Edward Island, Charlottetown, Prince Edward Island, Canada C1A \\ 4P3, ${ }^{2}$ National Research Council Institute for Nutrisciences and Health, Charlottetown, Prince Edward Island, Canada C1A 4P3, ${ }^{3}$ Department of Psychiatry \\ and Behavioral Sciences, Baylor College of Medicine, Houston, Texas 77030, and ${ }^{4}$ Amarin Neuroscience, Oxford OX4 4GA, United Kingdom
}

\begin{abstract}
An increased inflammatory response and deficient synthesis of neurotrophic factors (NTFs) may contribute to the etiology of depression. However, the interrelationship between inflammation and NTFs is unknown. Recently, ethyl-eicosapentaenoate (EPA) has been used to treat depression. The mechanism by which EPA benefits depression is also unclear. Using the olfactory bulbectomized (OB) rat model of depression, this study evaluated two pathways from bulbectomy to the induction of depression-like changes (the inflammation-hypothalamic-pituitary-adrenal axis-stress response pathway and inflammation-nerve growth factor-memory pathway) and the effect of EPA on these pathways. When compared with sham-operated rats fed a control diet, significantly increased locomotor and rearing activities in an "open field," impaired memory in the Morris water maze, increased expression of corticotrophin-releasing factor (CRF), and increased secretion of corticosterone were found in OB rats. mRNA expression of nerve growth factor (NGF) was significantly lower in the hippocampus, and phospholipase A2 (PLA2) was higher in the hypothalamus; this change was associated with increased interleukin-1 $\beta$ (IL-1 $\beta$ ) and prostaglandin E2 (PGE2) in the serum and brain. EPA treatments normalized these behavioral impairments and reduced CRF expression and corticosterone secretion. EPA also reduced serum concentrations of IL-1 $\beta$ and PGE2, but reversed NGF reduction. Similar to the effects of EPA, the anti-inflammatory drug celecoxib significantly reduced blood PGE2, IL-1 $\beta$, and corticosterone concentrations and increased NGF expression in OB rats. Furthermore, anti-NGF treatment blocked EPA effects on behavior. These results suggest that an interaction exists between inflammation and NGF in the depression model. EPA may improve depression via its anti-inflammation properties and the upregulation of NGF.
\end{abstract}

Key words: depression model; behavior; inflammation; EPA; NGF; celecoxib

\section{Introduction}

Inflammation may play an important role in major depression for multiple reasons. First, stress, as a trigger for depression, can increase inflammatory responses (Maes et al., 1998; Calcagni and Elenkov, 2006; Pace et al., 2007). Second, proinflammatory cytokines can stimulate the hypothalamic-pituitary-adrenal (HPA) axis to release glucocorticoids through the phospholipase A2 (PLA2)-prostaglandin E2 (PGE2)-corticotropin-releasing factor pathway (Engblom et al., 2002; Song et al., 2007). Third, proinflammatory cytokines can activate indoleamine 2,3dioxygenase, which may reduce the availability of the serotonin precursor tryptophan to the brain (Song et al., 1998; Wichers et

\footnotetext{
Received July 29, 2008; revised 0ct. 9, 2008; accepted Nov. 13, 2008.

This work was supported by Amarin Neuroscience and the Canadian Institutes of Health Research. We thank Xuwen Li, Zhijian Kang, and Yoshie Kadotomi for their technical support.

Correspondence should be addressed to Dr. Cai Song, Department of Biomedical Sciences, University of Prince Edward Island, 550 University Avenue, Charlottetown, Prince Edward Island, Canada C1A 4P3. E-mail: cai.song@nrc.gc.ca.

D01:10.1523/JNEUROSCI.3569-08.2009

Copyright $\odot 2009$ Society for Neuroscience $\quad$ 0270-6474/09/290014-09\$15.00/0
}

al., 2005). Recently, a neurotrophin hypothesis of depression has been raised because (1) neurodegenerative symptoms occur in depression, which is associated with a decrease in blood or brain concentrations of neurotrophic factors (NTFs), (2) antidepressant treatments increase the expression of NTFs, (3) NTFs can protect noradrenergic and serotonergic neurons, and (4) glucocorticoids and inflammation may suppress NTF synthesis (Mamounas et al., 1995; Quintero et al., 2004; Dranovsky and Hen, 2006; Castrén et al., 2007; Leonard, 2007; Post, 2007; Rajkowska and Miguel-Hidalgo, 2007; Schmidt and Duman, 2007). Decreased nerve growth factor (NGF) has been reported in several animal models of depression (Hellweg et al., 2002; von Richthofen et al., 2003; Schulte-Herbrüggen et al., 2006). However, the relationship between inflammation and NTFs in depression remains unknown.

Increasing evidence suggests that omega (n)-3 fatty acids have antidepressant and neuroprotective effects (Peet and Stokes, 2005; Lynch et al., 2007). Decreased n-3 fatty acids but an increased n-6/n-3 ratio occurs in depressed patients (Maes et al., 1999). Blood concentrations of n-3 fatty acids may reflect n-3 
fatty acid levels in the brain because $n-3$ fatty acids can cross the blood-brain barrier (Edmond, 2001; Yehuda et al., 2005).

The n-6 fatty acid arachidonic acid is a precursor of eicosanoids, which produce PGE2 and other inflammatory compounds through the action of PLA2. Increased cytosolic PLA2 (cPLA2) activity has been related to the dysfunction of neurotransmitter systems and the HPA axis in depressed patients ( $\mathrm{Hi}-$ bbeln et al., 1989; Pae et al., 2004). In contrast, a high intake of n-3 fatty acids like eicosapentaenoic acid (EPA) can inhibit inflammation. We have previously reported that EPA can significantly suppress stress and anxiety-like behavior as well as decrease corticosterone secretion induced by the proinflammatory cytokine interleukin-1 (IL-1) (Song et al., 2003, 2004). However, the mechanism by which EPA improves depressive symptoms has not been fully elucidated.

In the present study, olfactory bulbectomized (OB) rats, a valid depression model (Song and Leonard, 2005), were used to test two hypotheses: (1) inflammation may contribute to the stress-like response by increasing the activity of the HPA axis, and it may impair memory by decreasing the expression of NGF; and (2) the benefit of the n-3 fatty acid EPA to depression may be via anti-inflammation and NGF upregulation. To demonstrate these hypotheses, a COX2 inhibitor celecoxib and anti-NGF were costudied (see Fig. 1). If inflammation induces depression-like behavior, EPA might improve the behavior via its antiinflammation properties. Thus, treatment with a COX-2 inhibitor should have similar effects as treatment with EPA. Second, if inflammation suppresses NGF expression, the COX2 inhibitor and EPA should attenuate NGF reduction. Finally, if NGF plays a role in the neurodegenerative symptoms of depression (e.g., memory impairment), EPA might improve memory by upregulating NGF, whereas anti-NGF may block EPA's effect on memory.

\section{Materials and Methods}

Experimental design and procedure. There were four independent experiments (Exps.) in this study. In Exp. 1, 40 animals were divided into four groups $(n=10)$ : (1) sham operated $+1 \%$ palm oil (control diet), (2) OB $+1 \%$ palm oil, (3) sham $+1 \%$ EPA, and (4) OB $+1 \%$ EPA. Palm oil and EPA were fed to animals for 7 weeks. Six weeks after diet feeding and 4 weeks after bulbectomy, animal behavior was tested in a novel and stressful environment "open field" and Morris water maze task, respectively. After behavioral tests, animals were allowed to rest for $1 \mathrm{~d}$. Then, animals were decapitated, blood samples collected, and brains rapidly removed and dissected on ice. The concentrations of PGE2 and IL-1 were measured in the serum. The mRNA expression and activity of cPLA2 as well as the mRNA expression of NGF were measured in the hippocampus, amygdala, and hypothalamus. In Exp. 2, the groups and treatments were the same as those in Exp. 1. Corticotrophin-releasing factor (CRF) mRNA expression was measured by quantitative PCR in the paraventricular nucleus (PVN) of the hypothalamus by a micropunch technique (Song et al., 2007). The level of corticosterone was assayed in the serum. In Exp. 3, 40 animals were divided into four groups $(n=10)$ : (1) sham + saline, (2) $\mathrm{OB}+$ saline, (3) sham + celecoxib $(5 \mathrm{mg} / \mathrm{kg})$, and (4) $\mathrm{OB}+$ celecoxib (5 mg/kg in 10\% dimethyl sulfoxide, i.p.; Sigma) (Gobbo and O’Mara, 2004; Müller et al., 2006). After 4 weeks of treatment, serum concentrations of IL-1, PGE2, and corticosterone, NGF expression in the hippocampus, PGE2 concentrations in the hypothalamus, and animal behavior in the open field were evaluated. In Exp. 4, 30 animals were divided into three groups $(n=10)$ : (1) OB + palm oil, (2) OB + EPA, and (3) OB + EPA + anti-NGF (Sigma). The feeding time for EPA was 7 weeks, and anti-NGF $(12 \mu \mathrm{l})$ was intracerebroventricularly administrated for 10 d (Nabeshima et al., 1991; Nitta et al., 1996). Animal learning and memory were tested in the Morris water maze for $6 \mathrm{~d}$. After decapitation, brains were quickly removed on ice and OB surgery checked for each experiment. Rats with incomplete bulbectomy or frontal cortex damage were excluded before analysis of the results.

Animals and diets. Male Sprague Dawley rats (200-220 g and 2 months old at the start of the experiment) were purchased from Charles River. Food and water were available ad libitum. The colony was maintained at $22 \pm 1^{\circ} \mathrm{C}$ with a $12 \mathrm{~h}$ light-dark cycle (7:30 A.M. to 7:30 P.M.). Animals were handled daily. The research protocol was approved by the Animal Care Committees of the Universities of British Columbia and Prince Edward Island and conformed to the guidelines of the Canadian Council for Animal Care.

One percent palm oil that contained a negligible amount of $n-3$ and low n-6 fatty acids was added to rat-chow powder as a control diet to ensure comparable texture and caloric value as the 1\% EPA diet. Palm oil (Harlan Teklad Test Diet) was melted in a water bath $\left(<50^{\circ} \mathrm{C}\right)$. The rat chow powder was mixed with the palm oil or EPA (Amarin Neuroscience/Laxdale). The food was prepared every $3-4 \mathrm{~d}$ and stored at $4{ }^{\circ} \mathrm{C}$ (Song and Horrobin, 2004; Song et al., 2004). The feeding period was 7 weeks (Song et al., 2003). Before behavioral tests, rats were $\sim 3.6$ months old.

Surgery. Bilateral olfactory bulbectomy was performed under ketamine (100 mg/kg, i.p.) and xylazine $(20 \mathrm{mg} / \mathrm{kg}$, i.p.) anesthesia. The surgical procedure was the same as that described by van Riezen and Leonard (1990). In brief, a midline longitudinal incision was made from $1 \mathrm{~cm}$ posterior to and $1 \mathrm{~cm}$ anterior to the bregma. Burr holes, $2 \mathrm{~mm}$ in diameter, were then drilled through the skull $8 \mathrm{~mm}$ anterior to the bregma and $2 \mathrm{~mm}$ to either side of the midline. The olfactory bulbs were removed by suction, with care being taken to avoid damage to the frontal cortex. The burr holes were then filled with a hemostatic sponge. Tetracycline powder was applied to the wound. The skin was closed with 7.5 $\mathrm{mm}$ surgical clips. Sham-operated rats were treated in the same way, but the olfactory bulbs were not removed.

In Exp. 3, rats were anesthetized with the same drugs. For intracerebroventricular anti-NGF administration, a 20 gauge guide cannula containing a removable 24 gauge obturator was stereotaxically implanted at the lateral cerebral ventricle as described by Song et al. (2003). The cannulas were secured to the skull with four screws and dental cement.

Open field. The wall of the apparatus was made of aluminum and consisted of a white open circular floor. Faint brown grids were marked on the floor of the apparatus to divide it into 60 squares of $10 \mathrm{~cm}^{2}$ for quantifying locomotor activity. A $60 \mathrm{~W}$ bulb (white) was positioned 90 $\mathrm{cm}$ above the center of the apparatus. Rats were placed singly in the center of the apparatus. The number of squares crossed, rearing times (i.e., when a rat stood completely erect on its hind legs), grooming times (i.e., when a rat scratched its face with its forepaws), defecation, and the number of entries into the central zone of the apparatus were recorded for a period of $3 \mathrm{~min}$ (Gray and Lalljee, 1974). The apparatus was cleaned thoroughly with water after each animal had been tested.

Morris water maze. The apparatus and test for spatial learning and memory were the same as described by Song and Horrobin (2004). The water tank was $1.2 \mathrm{~m}$ deep and $2.0 \mathrm{~m}$ in diameter, and was divided into four quadrants of equal size (north, west, south, and east). The water depth was $80 \mathrm{~cm}$, and a platform was situated $2 \mathrm{~cm}$ below the water level. Water temperature was held at $26 \pm 1{ }^{\circ} \mathrm{C}$. On day 0 , rats were singly placed in a pool of water without the platform and allowed to swim freely for $1 \mathrm{~min}$. On day 1, a platform was positioned in one of the quadrants of the maze. Each rat was put into the maze facing the wall at one of four starting directions over five trials. Animals were allowed to stay in the water for $60 \mathrm{~s}$. Any rat that could not find the platform within $60 \mathrm{~s}$ was placed on the platform by the investigator and allowed to stay there for $15 \mathrm{~s}$. On days 2 and 3 , animals were trained with the same procedure as on day 1 . On day 4 , the platform was relocated to a different quadrant of the maze and the latency to locate the platform recorded. This training procedure was repeated on day 5 . The swimming speed, path lengths, angles of swimming, and latency to find the hidden platform were recorded by a video camera and computer system and analyzed by a computer (hardware and software provided by HVS Image).

Quantitative reverse transcription-PCR. mRNA expressions of NGF, $\mathrm{CRF}$, and cPLA2 were studied in the hippocampus, amygdala, and hypothalamus by quantitative reverse transcription (RT)-PCR. The total RNA 
was purified from these brain regions using an RNeasy Mini Kit (Qiagen). cDNA was synthesized from $2 \mu \mathrm{g}$ of total RNA using an Omniscript RT kit (Qiagen). Primer sequences were purchased from Invitrogen: for CPLA2, 5'-TTAACCTGCCGTATCCCTTGA- $3^{\prime}$ and $5^{\prime}$-AATGGAGGGCTGTCACT-3'; for NGF, 5'-GAAACGGAGACTCCGTTCACC- ${ }^{\prime}$ and $5^{\prime}$-GATTGTACCATGGGCCTGGA3'; for CRF, 5' ${ }^{\prime}$-TGTGTCCCATACCCGCAAG-3' and TCGCCCTTTCGGACATCAT-3'; for $\beta$-actin, $5^{\prime}$-TGTGGATTGGTGGCTCTATCC-3' and 5'-CGGACTCATCGTACTCCTGCT- $3^{\prime}$. The real-time PCR was performed with a QuantiTect SYBRGreen PCR Kit (Qiagen) at conditions of the initial activation at $95^{\circ} \mathrm{C}$ for $15 \mathrm{~min}$, denaturation at $94^{\circ} \mathrm{C}$ for $15 \mathrm{~s}$, annealing at $55^{\circ} \mathrm{C}$ for $20 \mathrm{~s}$, and extension at $72^{\circ} \mathrm{C}$ for $15 \mathrm{~s}$ with a single fluorescence measurement for up to 45 cycles. Then, a melt step was provided with temperature ramps set from 40 to $95^{\circ} \mathrm{C}$. The values were normalized against the endogenous control, $\beta$-actin. A sample from the control group was used as an external calibrator across all measurements.

Corticosterone, $I L-1$, and PGE2 assays. Serum samples from trunk blood of Exp. 2 were used for the corticosterone assay with a commercial radioimmunoassay kit (Immuchem corticosterone RIA kit for rats; catalog no. RCBK9906A; ICN Biochemical). Intra-assay and interassay coefficients of variation were $6.8 \%$ and $5.6 \%$, respectively.

The serum concentration of IL- $1 \beta$ was measured by the ELISA method according to the instructions with the kit, and the method was the same as that described by Song et al. (2004). The intra-assay CV values were 4.6.

The concentrations of PGE2 in the serum and hypothalamus (the supernatant of homogenized and sonicated brain tissue) were measured by an enzyme immunoassay (Assay Designs). The assay method was the same as that described previously (Song et al., 1998, 2004). In brief, standards and samples $(50 \mu \mathrm{l})$ were pipetted into the wells of plates coated with specific PGE2 antibodies and then incubated at $37^{\circ} \mathrm{C}$. After washing away any unbound ligand, an enzyme-linked polyclonal antibody specific for PGE2 was added to the wells and incubated at $37^{\circ} \mathrm{C}$. After removal of any unbound antibody-enzyme reagent, a substrate solution was added to the wells. The density of the color was proportional to the amount of protein bound. The intensity of the color was measured at a wavelength of $405 \mathrm{~nm}$ by a microtiter plate reader (Song et al., 1998).

Measurement of $c$ PLA2 activities. The hypothalamus was homogenized with a sonicator in ice-cold PBS. The protein concentration was determined in the homogenates with a Coomassie Plus Protein Assay Kit (Pierce) according to the manufacturer's protocol.

The cPLA2 activity was measured with an assay kit (Cayman Chemicals) as described by Bosetti and Weerasinghe (2003). Briefly, $1.5 \mathrm{~mm}$ arachidonoyl thio-PC (1-O-hexadecyl-2-deoxy-2-thio- $R$-(arachidonoyl)-snglyceral-3-phosphorylcholine) in the kit was used as a synthetic substrate to detect PLA2 activity. Each sample was homogenized in $0.5 \mathrm{ml}$ of ice-cold buffer $10 \mathrm{~mm}$ Tris buffer PH 7.8 (1\% Nonidet P-40, $0.15 \mathrm{~m} \mathrm{NaCl}$, and $1 \mathrm{~mm}$ EDTA, 2 mM dithiothreitol, $10 \mu \mathrm{M}$ phenylmethylsulfonyl fluoride, $9.2 \mu \mathrm{M}$ aprotinin, $0.11 \mu \mathrm{M}$ leupeptin, and $10.2 \mu \mathrm{m}$ pepstatin A). Cytosolic fractions were obtained by centrifuging at $18,000 \times g$ for $15 \mathrm{~min}$ at $4^{\circ} \mathrm{C}$ (Rintala et al., 1999). cPLA2 activity was determined in the cytosolic fractions with the presence of the iPLA2-specific inhibitor bromoenol lactone $(10 \mu \mathrm{M})$ and the sPLA2-specific inhibitor thioetheramide-PC $(50 \mu \mathrm{M})$, which were incubated with the samples for $20 \mathrm{~min}$ at $25^{\circ} \mathrm{C}$ before the assay. According to the method of Ghelardoni et al. (2004), the assay was repeated and verified in the presence of $50 \mu \mathrm{mol} / \mathrm{L}$ cPLA2-specific inhibitor arachidonyl trifluoromethyl ketone (AACOCF3) to confirm the reliability of this assay for CPLA2.

Statistics. A repeated two-way ANOVA (surgery $\times$ diet) was applied to data from the water maze test, whereas a two-way ANOVA was used for analyzing other data from Exps. 1-3. A one-way ANOVA was used for the results from Exp. 4. Differences between groups were assessed by the Newman-Keuls post hoc test (the package was from GB-STAT, Dynamic Microsystems). Significance was set at $p<0.05$. Results are expressed as mean \pm SEM.
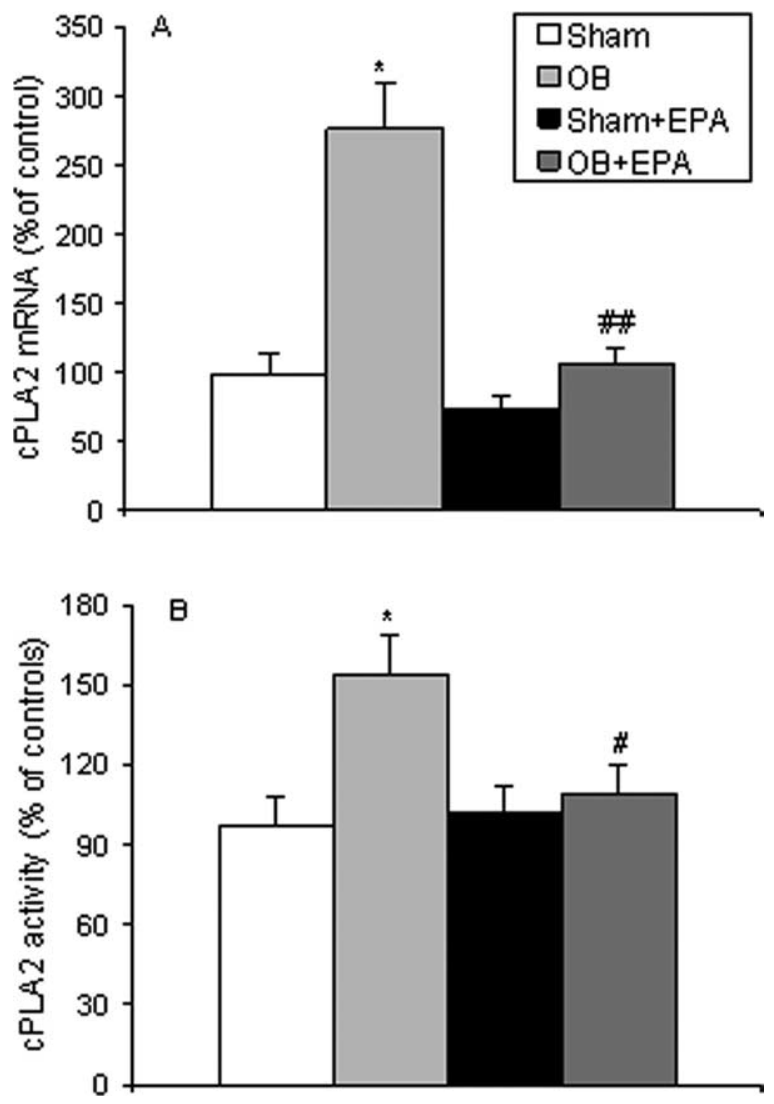

Figure 2. Effects of a diet enriched with EPA on $0 B$-induced changes in the expression of mRNA $(\boldsymbol{A})$ and activity of $\mathrm{CPLA2}(\boldsymbol{B})$ in the hypothalamus. ${ }^{*} p<0.01$ versus sham-operated rats; ${ }^{\#} p<0.05,{ }^{\# \#} p<0.01$ versus 0 B rats fed palm oil $(n=8-10)$.

\section{Results}

The order in which the results are presented here is the same as the order of the pathway shown in Figure 1.

\section{mRNA expression and activity of cPLA2}

The two-way ANOVA indicated that $\mathrm{OB}$ surgery significantly changed the mRNA expression $\left(F_{(1,32)}=18.89, p<0.001\right)$ and activity $\left(F_{(1,32)}=13.89, p<0.001\right)$ of cPLA2 in the hypothalamus (Fig. 2) but not other brain regions (result not shown). EPA has a significant interaction with $\mathrm{OB}$ surgery $\left(\mathrm{mRNA}: F_{(1,32)}=11.23\right.$, $p<0.01$; concentration: $\left.F_{(1,32)}=12.93, p<0.01\right)$. The Newman-Keuls post hoc test showed that increases in the expression and concentration of PLA2 (expressed as the percentage of control) were found in the OB group fed palm oil (OB-palm) $(p<$ 0.01 ) when compared with sham-operated rats fed the same diet (Sham-palm). These increases were significantly attenuated by 

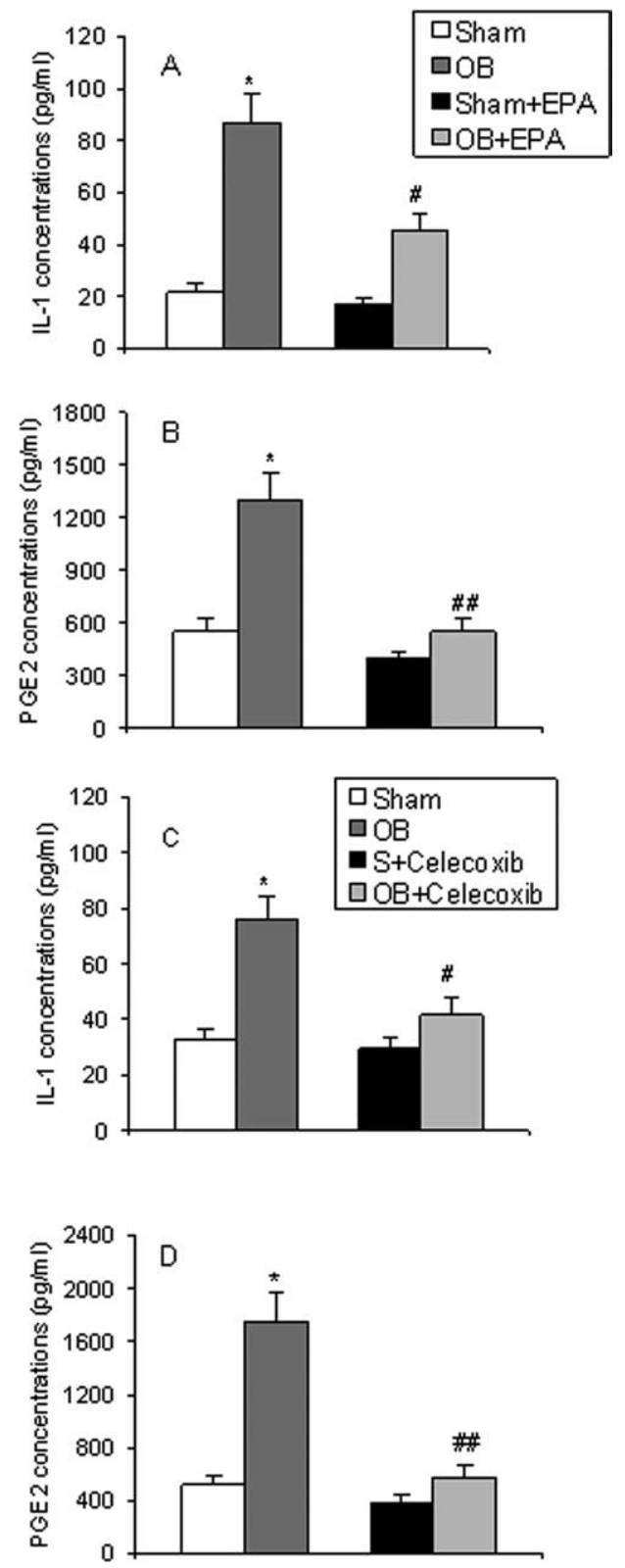

Figure 3. Effects of a diet enriched with EPA and the $\mathrm{CO}_{2}$ inhibitor celecoxib on serum concentrations of IL-1 $(\boldsymbol{A}, \boldsymbol{C})$ and PGE2 $(\boldsymbol{B}, \boldsymbol{D})$ in $0 \mathrm{~B}$ and sham-operated rats, respectively. ${ }^{*}<$ 0.01 versus sham-operated rats; ${ }^{\#} p<0.05,{ }^{\# \#} p<0.01$ versus 0 B rats fed palm oil $(n=8-10)$.

EPA treatment $(p<0.01$ for the mRNA and $p<0.05$ for the concentration) (Fig. $2 A, B$ ).

\section{Concentrations of IL-1 $\beta$ and PGE2}

The two-way ANOVA indicated a significant effect of OB surgery on serum IL- $1 \beta$ and PGE2 concentrations (IL-1: $F_{(1,32)}=7.96$, $p<0.01$; PGE2: $\left.F_{(1,32)}=6.88, p<0.01\right)$. The post hoc test showed a significant increase in IL- $1 \beta$ and PGE2 levels in the serum of the OB-palm group compared with the Sham-palm group $(p<$ 0.01). The ANOVA also indicated an interaction between EPA treatment and OB surgery (IL-1: $F_{(1,32)}=6.62, p<0.05$; PGE2: $\left.F_{(1,32)}=8.89, p<0.01\right)$. The Newman-Keuls test revealed that EPA treatment significantly reduced both concentrations of these proinflammatory mediators $(p<0.05$ and $p<0.01$, respectively) (Fig. 3A,B).

In Exp. 3, higher levels of serum IL-1 $\beta$ and PGE2 were also found in the OB-palm group than the Sham-palm group $(p<$ 0.05). Celecoxib treatment, similar to the effects of EPA, markedly reduced IL-1 and PGE2 concentrations in the serum of OB rats $\left(\mathrm{IL}-1: F_{(1,32)}=5.93, p<0.05\right.$; PGE2: $\left.F_{(1,32)}=8.48, p<0.01\right)$ (Fig. $3 C, D)$. Similar results were found in the hypothalamus: the PGE2 concentration was higher in $\mathrm{OB}$ rats than in sham rats $\left(F_{(1,32)}=7.24, p<0.01\right)$, and it was attenuated by celecoxib treatment $\left(F_{(1,32)}=9.43, p<0.01\right)$. Sham: $1435 \pm 160$; OB: $2376 \pm 260$; celecoxib: $1026 \pm 121$; OB with celecoxib: $1572 \pm$ 149 (results are expressed as $\mathrm{ng} / \mathrm{g}$ brain tissue).

\section{CRF mRNA expression and blood corticosterone concentration}

The two-way ANOVA showed that OB surgery caused significant differences in CRF mRNA expression in the PVN of the hypothalamus and in serum concentration of corticosterone (CRF: $F_{(1,32)}$ $=7.83, p<0.01$; corticosterone: $\left.F_{(1,32)}=9.62, p<0.01\right)$. The post hoc test revealed that a significant increase in CRF expression and the serum concentration of corticosterone occurred in the OB-palm group $(p<0.01)$ compared with the Sham-palm group. Additionally, the ANOVA indicated an interaction between diet and OB surgery (CRF: $F_{(1,32)}=6.54, p<0.05$; corticosterone: $\left.F_{(1,32)}=5.83, p<0.05\right)$. The post hoc test between groups confirmed that EPA treatment significantly reduced both CRF expression and corticosterone concentration compared with the OB-palm group $(p<0.05)$ (Fig. $4 A, B)$. Celecoxib treatment significantly blocked the elevation of corticosterone levels in $\mathrm{OB}$ rats $\left(F_{(1,32)}=6.82, p<0.05\right)$, which is similar to the effect of EPA (Fig. 4C).

\section{NGF expression in the hippocampus}

In Exp. 1, the diet and lesion-induced significant change in NGF mRNA expression was only found in the hippocampus $\left(F_{(1,24)}=\right.$ $15.84, p<0.001)$, not in the hypothalamus or amygdala. The Newman-Keuls post hoc revealed that NGF expression was increased in sham animals fed EPA (Sham-EPA) when compared with the Sham-palm group $(p<0.01)$ (Fig. 5). However, a significant decrease in NGF expression was found in the OB-palm group when compared with the Sham-palm group $(p<0.01)$. A two-way ANOVA also indicated a significant interaction between $\mathrm{OB}$ and $\operatorname{diet}\left(F_{(1,24)}=6.38, p<0.05\right)$. The post hoc test between groups showed that EPA treatment significantly reversed the reduction of NGF mRNA expression in OB animals $(p<0.05)$ (Fig. 5A).

Exp. 3 further confirmed the reduction of NGF expression in the hippocampus of $\mathrm{OB}$ rats receiving a saline injection $\left(F_{(1,24)}=\right.$ $10.73, p<0.01)$. The reduction was attenuated by chronic celecoxib treatment $\left(F_{(1,32)}=9.92, p<0.01\right)$ (Fig. $\left.5 B\right)$.

\section{Behavior changes in OB rats and effects of EPA and celecoxib treatments}

In the "open field," locomotor activity and rearing scores were significantly increased in the OB-palm group compared with the sham-palm group (locomotor: $F_{(1,32)}=14.73, p<0.01$; rearing: $\left.F_{(1,32)}=8.08, p<0.01\right)$. EPA treatment did not significantly change animal behavior in sham rats. However, OB-induced behavioral changes in the open field were significantly attenuated by EPA treatment (locomotor: $F_{(1,32)}=19.96 ; p<0.001$; rearing: $\left.F_{(1,32)}=16.98, p<0.01\right)($ Table 1$)$. Similar hyperactive behaviors were also found in the OB-palm group in the Exp. 3 (locomotor: $F_{(1,32)}=12.75, p<0.01$; rearing: $\left.F_{(1,32)}=7.46, p<0.05\right)$. Similar to EPA, celecoxib significantly attenuated both behavioral 

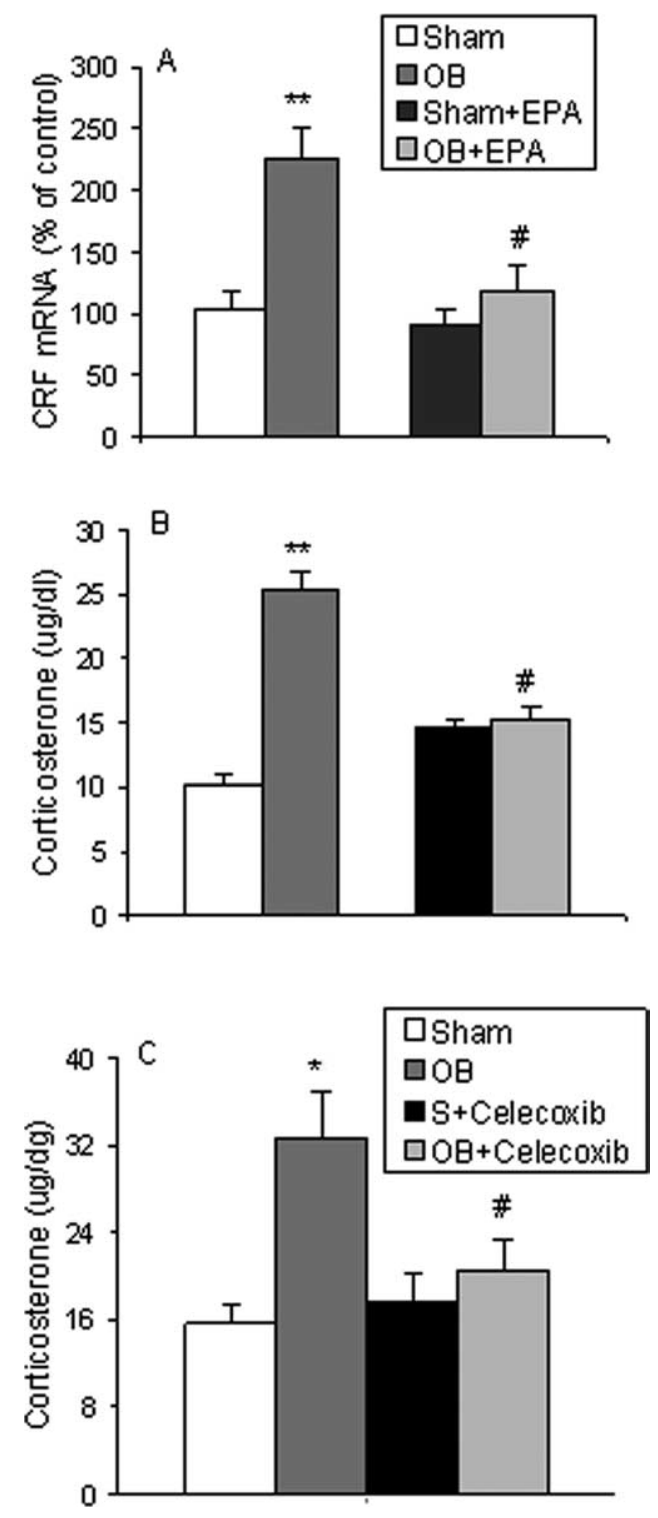

Figure 4. Effects of a diet enriched with EPA and the $\mathrm{CO}_{2}$ inhibitor celecoxib on the mRNA expression of PVN CRF $(\boldsymbol{A})$ and serum concentrations of corticosterone $(\boldsymbol{B}, \boldsymbol{C})$ in $\mathrm{OB}$ and shamoperated rats, respectively. ${ }^{*} p<0.05,{ }^{* *} p<0.01$ versus sham-operated rats; ${ }^{\#} p<0.05$ versus $\mathrm{OB}$ rats fed palm oil $(n=8-10)$.

changes (locomotor: $F_{(1,32)}=10.83, p<0.01$; rearing: $F_{(1,32)}=$ 9.85; $p<0.01$ ) (Table 1).

In the water maze, there was no significant difference between sham and $\mathrm{OB}$ groups on days 1 and 2. On days 3, 4, and 5, members of the OB-palm group took longer to find the platform than sham controls (day 3: $F_{(1,32)}=22.26, p<0.01$; day 4: $F_{(1,32)}$ $=9.43, p<0.05$; day $\left.5: F_{(1,32)}=13.65, p<0.01\right)$ (Fig. $\left.6 A\right)$. In the EPA feeding groups, there was no difference in the latency to find the platform between sham and $\mathrm{OB}$ animals. However, the ANOVA indicated a significant interaction between OB and EPA treatment on days 3, 4, and 5 (day 3: $F_{(1,32)}=5.06, p<0.01$; day $4: F_{(1,32)}=3.35, p<0.05$; day $\left.5: F_{(1,32)}=6.21, p<0.01\right)$. The post $h o c$ analysis revealed a significant difference between the OBpalm and OB-EPA groups ( $p<0.05$ or 0.01 ) (Fig. $6 A$ ), suggesting that EPA markedly improved spatial memory in $\mathrm{OB}$ rats.

In Exp. 4, the one-way ANOVA indicated that EPA treatment significantly improved $\mathrm{OB}$ animal spatial memory in the water maze $\left(F_{(1,29)}=8.82, p<0.01\right)$. In contrast, chronic anti-NGF
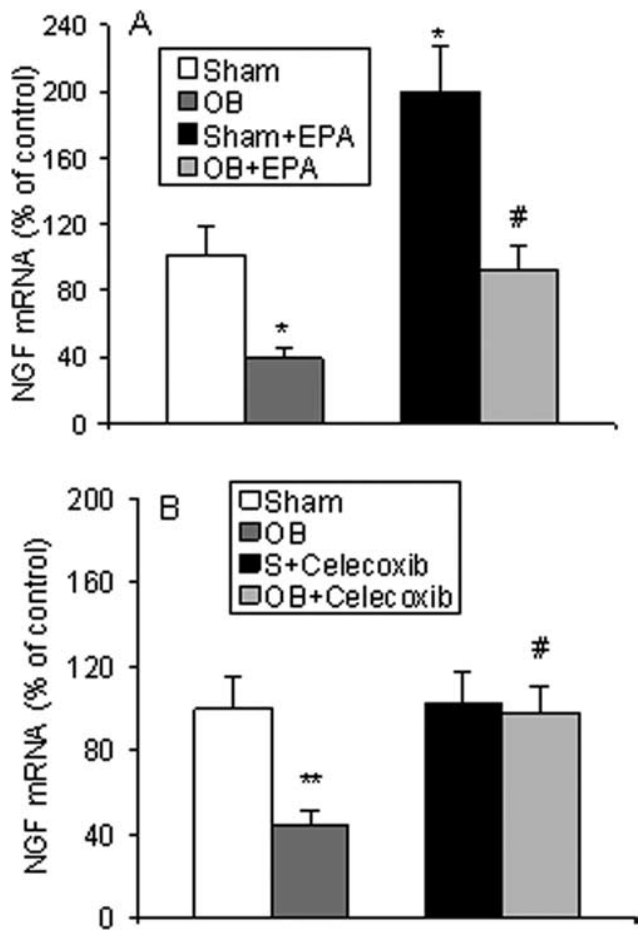

Figure 5. Effects of a diet enriched with EPA $(\boldsymbol{A})$ and the $\mathrm{CO}_{2}$ inhibitor celecoxib $(\boldsymbol{B})$ on the mRNA expression of NGF in the hippocampus of $0 B$ and sham-operated rats. ${ }^{*} p<0.05$, ${ }^{* *} p<$ 0.01 versus sham-operated rats; ${ }^{\#} p<0.05$ versus $0 \mathrm{~B}$ rats fed palm oil $(n=8-10)$.

Table 1. The effects of EPA and celecoxib on animal behavior in an "open field"

\begin{tabular}{lllll}
\hline \multicolumn{1}{c}{ Palm } & EPA & Saline & Celecoxib \\
\hline Locomotor & & & & \\
$\quad$ Sham & $75.71 \pm 6.83$ & $69.86 \pm 9.26$ & $83.45 \pm 9.26$ & $79.83 \pm 6.77$ \\
OB & $110.41 \pm 10.02^{*}$ & $64.29 \pm 7.03^{\#}$ & $120.67 \pm 11.73^{*}$ & $79.46 \pm 8.62^{\#}$ \\
Rearing & & & & \\
Sham & $12.3 \pm 1.54$ & $12.93 \pm 10.24$ & $12.93 \pm 10.21$ & $13.57 \pm 1.25$ \\
OB & $20.4 \pm 2.32^{*}$ & $11.29 \pm 1.46^{\#}$ & $19.64 \pm 14.67^{*}$ & $11.72 \pm 12.2^{\#}$ \\
\hline
\end{tabular}

${ }^{*} p<0.05$ versus shams fed palm oil or treated with saline; ${ }^{\#} p<0.05$ versus $0 \mathrm{~B}$ rats fed palm oil or treated with saline $(n=8-10)$.

administration significantly blocked the effect of EPA $\left(F_{(1,29)}=\right.$ 6.43, $p<0.05$ ) (Fig. 6B).

\section{Discussion}

It has been extensively reported that changes in the behavior, neurotransmission, neuroendocrine, and immune functions of $\mathrm{OB}$ rats are similar to those observed in depressed patients (Song and Leonard, 2005). Using this animal model of depression, the present study demonstrated two important pathways: (1) PLA2inflammation-HPA activity-behavior (stress response) and (2) inflammation-NGF-memory impairment. cPLA2 triggers inflammation by releasing arachidonic acid, a precursor of eicosanoids (Phillis and O'Regan, 2004; Rosenberger et al., 2004) that produce PGE2 and proinflammatory mediators. Both PGE2 and the proinflammatory cytokine IL-1 can activate CRF-containing neurons in the paraventricular hypothalamic nucleus (PVN) (Engblom et al., 2002), and they then signal through ACTH to release corticosterone. In the present study, increased expressions of CPLA2 and CRF and elevated blood concentrations of PLA2 and PGE2 were reported for the first time in OB rats. An increase in IL-1 levels was also found in the OB rat, which is consistent with previous findings (Connor et al., 2000; Myint et al., 2007). These inflammation-related changes were correlated with the in- 

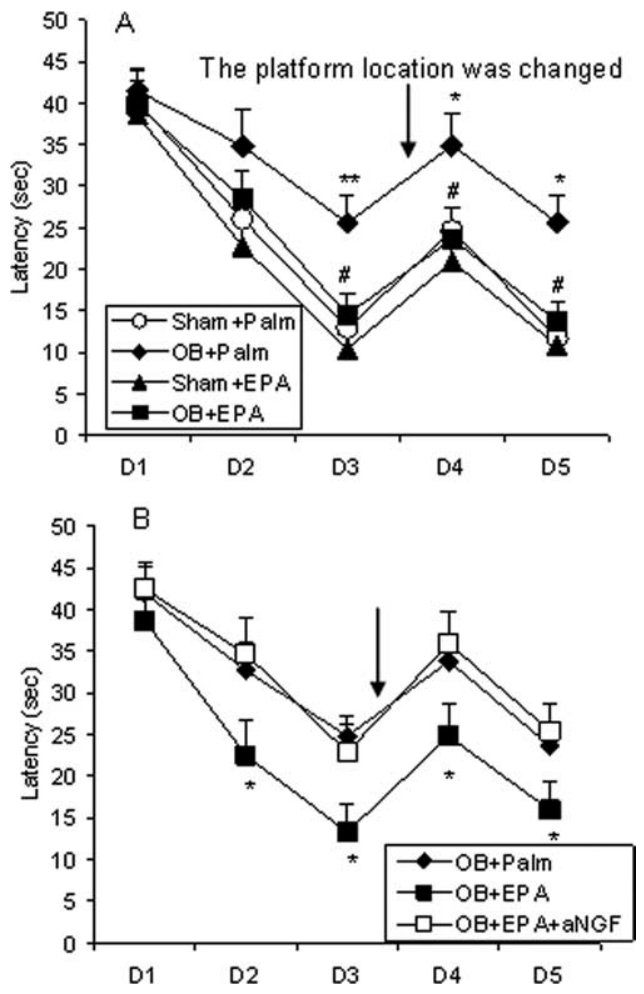

Figure 6. Effects of a diet enriched with EPA $(\boldsymbol{A})$ and anti-NGF $(\boldsymbol{B})$ on spatial memory in the Morris water maze in $O B$ and sham-operated rats. ${ }^{*} p<0.05,{ }^{* *} p<0.01$ versus shamoperated rats; ${ }^{\#} p<0.05$ versus 0 B rats fed palm oil $(n=8-10)$.

crease in corticosterone secretion and stress-like behavior in the "open field." Increased cPLA2 has also been reported in patients with major or bipolar depression (Noponen et al., 1993). Furthermore, the present study used the COX2 inhibitor celecoxib to demonstrate the pathway from inflammation to stress hormones and stress-like behavior. Thus, celecoxib significantly reduced both blood and brain PGE2 concentrations and decreased blood IL-1 levels. These changes were correlated with a decrease in corticosterone secretion and a decrease in stress-like behavior in $\mathrm{OB}$ rats. These results not only support a previous finding that celecoxib has therapeutic effects in major depression (Müller et al., 2006) but also reveal the possible mechanism by which the drug reduces stress hormone and stress-like behaviors by lowering inflammation.

As mentioned in the introduction, the newest hypothesis of depression postulates that the deficiency of NTFs is causally related to the etiology of depression. A postmortem study in suicide victims has shown decreased NGF protein levels in the frontal cortex and hippocampus (Dwivedi et al., 2005). Decreased NTF expression is associated with neuronal atrophy and cell loss both in depressed patients and after chronic stress exposure, in which the excessive secretion of glucocorticoids or enhanced inflammatory response may play a significant role (Duman, 2005; Leonard and Myint, 2006). Indeed, chronic psychological stress, a common component of depression, enhances glucocorticoid release and suppresses NGF mRNA expression in the hippocampus (Alfonso et al., 2004). Furthermore, antidepressant treatments or electroconvulsive shock therapy increases the expression and concentrations of NGF in the brain (Alfonso et al., 2006; Hellweg et al., 2008). However, dexamethasone or corticosterone treatment has been also reported to increase NGF expression in the several brain regions, including the hippocampus (Shi et al.,
1998). Nevertheless, the present study for the first time demonstrated the mechanism by which inflammation suppresses NGF expression in the OB depression model, because the antiinflammatory drug celecoxib decreases corticosterone release but reverses the reduction of NGF expression.

Previous studies by others also suggest that inflammation may suppress NTF function. For example, a study from an in vitro model of Alzheimer's disease (AD) induced by aluminum has shown that increased proinflammatory cytokines are correlated with the decrease in NGF and BDNF expression; further, the latter triggers the expression of apoptosis genes (Johnson and Sharma, 2003). The molecular mechanism could involve the modulation of proinflammatory cytokines via AP- $1, \mathrm{NF}-\kappa \mathrm{B}$, and CREB signals, which change NGF and BDNF functions (Otten et al., 2000; Wong et al., 2005). Conversely, NGF has been shown to suppress inflammation (Stampachiacchiere and Aloe, 2005). NGF administration reduced the immunoreactivity of major histocompatibility complex (MHC) class-II (proinflammation) and enhanced MHC class-I (helping cell recovery) after spinal cord injury (Stampachiacchiere and Aloe, 2005). However, several studies have reported that inflammation or brain injury increases NGF expression and synthesis (DeKosky et al., 1996; Heese et al., 1998). These conflicting results may be reconciled by the fact that inflammation in the brain is a double-edged process that promotes homeostasis but also results in cell death through potential damage from inflammatory mediators. Recently, we have reported that acute intracerebroventricular IL-1 administration increases, whereas chronic IL-1 decreases, BDNF expression in the hippocampus (Song et al., 2008). In addition, neurotrophin receptors like the TrKs (which may promote cell survival) and P75 (which may trigger apoptosis) respond differently to the various neurotrophin changes induced by inflammation (Friedman, 2005).

Another important finding from the present study is the series of mechanisms by which EPA ameliorates depression. n-3 and n-6 fatty acids are important components of the cell membrane. Changing the fatty acid content may influence brain structure and function. Epidemiological investigations have revealed a negative correlation between the intake of $n-3$ fatty acids and the onset or severity of depression (Cole et al., 2005; Parker et al., 2006). Several updated reviews have postulated that depression is causally connected with $\mathrm{AD}$ or dementia (Leonard and Myint, 2006; Fraise, 2007). Lower n-3 fatty acid concentrations were found in the blood or plasma of these patients (Maes et al., 1996; Connor and Connor, 2007). Thus, EPA has been used to treat depression (Peet, 2003; Nemets et al., 2006). In 11 clinical trials, eight investigations with pure EPA (1-2 g/d) showed significant effects and three trials with a combination of EPA and docosahexaenoic acid or with a high dose of EPA ( $4 \mathrm{~g} / \mathrm{d})$ failed. In the present study, we demonstrated that EPA can attenuate the stress-like response and improve memory in the OB model of depression. EPA may treat depression and improve memory via anti-inflammation (reduced PGE2 and IL-1 $\beta$ ), anti-stress (reduce CRF and corticosterone), and neuroprotection (upregulated NGF and normalized neurotransmitters) mechanisms. The anti-inflammation effect of EPA was observed in the present study, in which it reduced both cPLA2 expression and the concentrations of IL-1 and PGE2. These results are consistent with our previous findings that EPA decreased cPLA2 activity as well as PGE2 and IL-1 concentrations in the brain and blood of animals receiving IL-1 $\beta$ administration (Song et al., 2004, 2007). Because IL- 1 and PGE2 can activate the HPA axis (Engblom et al., 2002), one of the mechanisms by which EPA reduces CRF and 
corticosterone may be through the suppression of IL-1 and PGE2.

Inflammation and NTFs may play opposing roles in the cognitive impairment that often occurs in depressed patients. At physiological levels, IL-1 is an important factor for generating LTP and spatial memory. Suppressed LTP and impaired memory were observed in mice lacking the IL-1R or with IL-1RA overexpression (Avital et al., 2003). In contrast, the overproduction of IL- 1 in aging and disease conditions (e.g., AD and depression) or the exogenous administration of IL- $1 \beta$ suppresses LTP and impairs memory (Strijbos and Rothwell, 1995; Lynch, 1998; McGahon et al., 1999). IL-1 action on memory is probably mediated by cholinergic system (Song, 2009). Recently, Song et al. (2008) have reported that IL-1 $\beta$ administration for $7 \mathrm{~d}$ reduces acetylcholine (ACh) release from the dentate gyrus during the memory retrieval phase, which is associated with memory impairment and lower mRNA expression of hippocampal NGF. After EPA treatment for 7 weeks, ACh release, NGF expression, and memory performance were normalized (Song, 2009). In the present study, reduced NGF expression in the hippocampus is associated with spatial memory deficits in OB rats. EPA increased NGF and also improved memory. After blocking EPA's effect via anti-NGF administration, animal memory showed deficits again. Thus, the present study demonstrated that decreased NGF expression in the hippocampus also contributed to memory deficits in $\mathrm{OB}$ rats, whereas the mechanism by which EPA improved memory might involve the upregulation of NGF expression.

An increased inflammatory response may induce an imbalance between astrocyte and microglial activities and trigger the activation of indoleamine 2,3-dioxygenase and its subsequent enzyme kynurenine monooxygenase to cause serotonergic deficiency and glutamatergic overproduction (Müller and Schwarz, 2007). The dysfunction of astrocytes could also contribute to deficiencies of NGF and other NTFs. With regard to the glutamatergic system in cognitive degeneration and depression, Song's team has reported that IL-1 $\beta$ cultured with hippocampal neurons selectively downregulates AMPA receptor phosphorylation and surface expression through extracellular calcium (Lai et al., 2006). High doses of IL-1 could also exacerbate glutamate-, AMPA-, and NMDA-induced neuronal death (Strijbos and Rothwell, 1995). On the other hand, an imbalance between glutamatergic and GABAergic transmission was found after IL-1 administration (Zhu et al., 2006). After EPA treatment, the reduction of glutamate-induced excitotoxicity and attenuation of age-related decreases in the GluR2 and NR2B glutamate receptors have been reported in the rat (Xiao and Li, 1999; Dyall et al., 2007). Therefore, possible mechanisms by which EPA improves spatial memory in OB rats may result from EPA's suppression of inflammation and normalization of the cholinergic and glutamatergic systems.

A limitation of this study is a shortage of measurement of the fatty acid profile after EPA treatment. Many studies have demonstrated that n-3 and n- 6 diets change the composition of brain lipids, and such changes have been firmly related to their effects on neurotransmission and behavior (Chalon et al., 1998; Yeh et al., 1999; Innis and de La Presa Owens, 2001).

\section{References}

Alfonso J, Pollevick GD, Van Der Hart MG, Flügge G, Fuchs E, Frasch AC (2004) Identification of genes regulated by chronic psychosocial stress and antidepressant treatment in the hippocampus. Eur J Neurosci 19:659-666.

Alfonso J, Frick LR, Silberman DM, Palumbo ML, Genaro AM, Frasch AC (2006) Regulation of hippocampal gene expression is conserved in two species subjected to different stressors and antidepressant treatments. Biol Psychiatry 59:244-251.

Avital A, Goshen I, Kamsler A, Segal M, Iverfeldt K, Richter-Levin G, Yirmiya R (2003) Impaired interleukin-1 signaling is associated with deficits in hippocampal memory processes and neural plasticity. Hippocampus $13: 826-834$.

Bosetti F, Weerasinghe GR (2003) The expression of brain cyclooxygenase-2 is down-regulated in the cytosolic phospholipase A2 knockout mouse. J Neurochem 87:1471-1477.

Calcagni E, Elenkov I (2006) Stress system activity, innate and T helper cytokines, and susceptibility to immune-related diseases. Ann N Y Acad Sci 1069:62-76.

Castrén E, Võikar V, Rantamäki T (2007) Role of neurotrophic factors in depression. Curr Opin Pharmacol 7:18-21.

Chalon S, Delion-Vancassel S, Belzung C, Guilloteau D, Leguisquet AM, Besnard JC, Durand G (1998) Dietary fish oil affects monoaminergic neurotransmission and behavior in rats. J Nutr 128:2512-2519.

Cole GM, Lim GP, Yang F, Teter B, Begum A, Ma Q, Harris-White ME, Frautschy SA (2005) Prevention of Alzheimer's disease: omega-3 fatty acid and phenolic anti-oxidant interventions. Neurobiol Aging 26:133-136.

Connor TJ, Harkin A, Kelly JP, Leonard BE (2000) Olfactory bulbectomy provokes a suppression of interleukin-1beta and tumour necrosis factoralpha production in response to an in vivo challenge with lipopolysaccharide: effect of chronic desipramine treatment. Neuroimmunomodulation 7:27-35.

Connor WE, Connor SL (2007) The importance of fish and docosahexaenoic acid in Alzheimer disease. Am J Clin Nutr 85:929-930.

DeKosky ST, Styren SD, O’Malley ME, Goss JR, Kochanek P, Marion D, Evans CH, Robbins PD (1996) Interleukin-1 receptor antagonist suppresses neurotrophin response in injured rat brain. Ann Neurol 39:123-127.

Dranovsky A, Hen R (2006) Hippocampal neurogenesis: regulation by stress and antidepressants. Biol Psychiatry 59:1136-1143.

Duman RS (2005) Neurotrophic factors and regulation of mood: role of exercise, diet and metabolism. Neurobiol Aging 26:88-93.

Dwivedi Y, Mondal AC, Rizavi HS, Conley RR (2005) Suicide brain is associated with decreased expression of neurotrophins. Biol Psychiatry 58:315-324.

Dyall SC, Michael GJ, Whelpton R, Scott AG, Michael-Titus AT (2007) Dietary enrichment with omega- 3 polyunsaturated fatty acids reverses agerelated decreases in the GluR2 and NR2B glutamate receptor subunits in rat forebrain. Neurobiol Aging 28:424-439.

Edmond J (2001) Essential polyunsaturated fatty acids and the barrier to the brain: the components of a model for transport. J Mol Neurosci 16:181193; discussion 215-221.

Engblom D, Ek M, Saha S, Ericsson-Dahlstrand A, Jakobsson PJ, Blomqvist A (2002) Prostaglandins as inflammatory messengers across the bloodbrain barrier. J Mol Med 80:5-15.

Fraise AP (2007) Decontamination of the environment. J Hosp Infect 65 [Suppl 2]:58-59.

Friedman WJ (2005) Interactions of interleukin-1 with neurotrophic factors in the central nervous system: beneficial or detrimental? Mol Neurobiol 32:133-144.

Ghelardoni S, Tomita YA, Bell JM, Rapoport SI, Bosetti F (2004) Chronic carbamazepine selectively downregulates cytosolic phospholipase A2 expression and cyclooxygenase activity in rat brain. Biol Psychiatry $56: 248-254$.

Gray JA, Lalljee B (1974) Sex differences in emotional behaviour in the rat: correlation between open-field defecation and active avoidance. Anim Behav 22:856-861.

Heese K, Fiebich BL, Bauer J, Otten U (1998) NF-kappaB modulates lipopolysaccharide-induced microglial nerve growth factor expression. Glia 22:401-407.

Hellweg R, Lang UE, Nagel M, Baumgartner A (2002) Subchronic treatment with lithium increases nerve growth factor content in distinct brain regions of adult rats. Mol Psychiatry 7:604-608.

Hellweg R, Ziegenhorn A, Heuser I, Deuschle M (2008) Serum concentrations of nerve growth factor and brain-derived neurotrophic factor in depressed patients before and after antidepressant treatment. Pharmacopsychiatry 41:66-71.

Hibbeln JR, Palmer JW, Davis JM (1989) Are disturbances in lipid-protein 
interactions by phospholipase-A2 a predisposing factor in affective illness? Biol Psychiatry 25:945-961.

Innis SM, de La Presa Owens S (2001) Dietary fatty acid composition in pregnancy alters neurite membrane fatty acids and dopamine in newborn rat brain. J Nutr 131:118-122.

Johnson VJ, Sharma RP (2003) Aluminum disrupts the pro-inflammatory cytokine/neurotrophin balance in primary brain rotation-mediated aggregate cultures: possible role in neurodegeneration. Neurotoxicology 24:261-268.

Lai AY, Swayze RD, El-Husseini A, Song C (2006) Interleukin-1 beta modulates AMPA receptor expression and phosphorylation in hippocampal neurons. J Neuroimmunol 175:97-106.

Leonard BE (2007) Inflammation, depression and dementia: are they connected? Neurochem Res 32:1749-1756.

Leonard BE, Myint A (2006) Inflammation and depression: is there a causal connection with dementia? Neurotox Res 10:149-160.

Lynch AM, Loane DJ, Minogue AM, Clarke RM, Kilroy D, Nally RE, Roche OJ, O'Connell F, Lynch MA (2007) Eicosapentaenoic acid confers neuroprotection in the amyloid-beta challenged aged hippocampus. Neurobiol Aging 28:845-855.

Lynch MA (1998) Age-related impairment in long-term potentiation in hippocampus: a role for the cytokine, interleukin-1 beta? Prog Neurobiol 56:571-589

Maes M, Smith R, Christophe A, Cosyns P, Desnyder R, Meltzer H (1996) Fatty acid composition in major depression: decreased omega 3 fractions in cholesteryl esters and increased C20: 4 omega 6/C20:5 omega 3 ratio in cholesteryl esters and phospholipids. J Affect Disord 38:35-46.

Maes M, Song C, Lin A, De Jongh R, Van Gastel A, Kenis G, Bosmans E, De Meester I, Benoy I, Neels H, Demedts P, Janca A, Scharpé S, Smith RS (1998) The effects of psychological stress on humans: increased production of pro-inflammatory cytokines and a Th1-like response in stressinduced anxiety. Cytokine 10:313-318.

Maes M, Christophe A, Delanghe J, Altamura C, Neels H, Meltzer HY (1999) Lowered omega 3 polyunsaturated fatty acids in serum phospholipids and cholesteryl esters of depressed patients. Psychiatry Res 85:275-291.

Mamounas LA, Blue ME, Siuciak JA, Altar CA (1995) Brain-derived neurotrophic factor promotes the survival and sprouting of serotonergic axons in rat brain. J Neurosci 15:7929-7939.

McGahon BM, Martin DS, Horrobin DF, Lynch MA (1999) Age-related changes in LTP and antioxidant defenses are reversed by an alpha-lipoic acid-enriched diet. Neurobiol Aging 20:655-664.

Müller N, Schwarz MJ (2007) The immune-mediated alteration of serotonin and glutamate: towards an integrated view of depression. Mol Psychiatry 12:988-1000.

Müller N, Schwarz MJ, Dehning S, Douhe A, Cerovecki A, Goldstein-Müller B, Spellmann I, Hetzel G, Maino K, Kleindienst N, Möller HJ, Arolt V, Riedel M (2006) The cyclooxygenase-2 inhibitor celecoxib has therapeutic effects in major depression: results of a double-blind, randomized, placebo controlled, add-on pilot study to reboxetine. Mol Psychiatry 11:680-684.

Myint AM, Steinbusch HW, Goeghegan L, Luchtman D, Kim YK, Leonard BE (2007) Effect of the COX-2 inhibitor celecoxib on behavioural and immune changes in an olfactory bulbectomised rat model of depression. Neuroimmunomodulation 14:65-71.

Nabeshima T, Ogawa S, Yamada K, Ishimaru H, Fuji K, Kameyama T, Fukuta T, Takeuchi R, Hayashi K (1991) Memory impairment and morphological changes in rats after continuous infusion of active fragment of antinerve growth factor-antibody. Res Commun Chem Pathol Pharmacol $74: 141-152$.

Nemets H, Nemets B, Apter A, Bracha Z, Belmaker RH (2006) Omega-3 treatment of childhood depression: a controlled, double-blind pilot study. Am J Psychiatry 163:1098-1100.

Nitta A, Ogihara Y, Onishi J, Hasegawa T, Furukawa S, Nabeshima T (1996) Propentofylline prevents neuronal dysfunction induced by infusion of anti-nerve growth factor antibody into the rat septum. Eur J Pharmacol 307:1-6.

Noponen M, Sanfilipo M, Samanich K, Ryer H, Ko G, Angrist B, Wolkin A, Duncan E, Rotrosen J (1993) Elevated PLA2 activity in schizophrenics and other psychiatric patients. Biol Psychiatry 34:641-649.

Otten U, März P, Heese K, Hock C, Kunz D, Rose-John S (2000) Cytokines and neurotrophins interact in normal and diseased states. Ann N Y Acad Sci 917:322-330.
Pace TW, Hu F, Miller AH (2007) Cytokine-effects on glucocorticoid receptor function: relevance to glucocorticoid resistance and the pathophysiology and treatment of major depression. Brain Behav Immun 21:9-19.

Pae CU, Yu HS, Kim JJ, Lee CU, Lee SJ, Lee KU, Jun TY, Paik IH, Serretti A, Lee C (2004) BanI polymorphism of the cytosolic phospholipase A2 gene and mood disorders in the Korean population. Neuropsychobiology 49:185-188.

Parker G, Gibson NA, Brotchie H, Heruc G, Rees AM, Hadzi-Pavlovic D (2006) Omega-3 fatty acids and mood disorders. Am J Psychiatry 163:969-978.

Peet M (2003) Eicosapentaenoic acid in the treatment of schizophrenia and depression: rationale and preliminary double-blind clinical trial results. Prostaglandins Leukot Essent Fatty Acids 69:477-485.

Peet M, Stokes C (2005) Omega-3 fatty acids in the treatment of psychiatric disorders. Drugs 65:1051-1059.

Phillis JW, O’Regan MH (2004) A potentially critical role of phospholipases in central nervous system ischemic, traumatic, and neurodegenerative disorders. Brain Res Brain Res Rev 44:13-47.

Post RM (2007) Role of BDNF in bipolar and unipolar disorder: clinical and theoretical implications. J Psychiatr Res 41:979-990.

Quintero EM, Willis LM, Zaman V, Lee J, Boger HA, Tomac A, Hoffer BJ, Strömberg I, Granholm AC (2004) Glial cell line-derived neurotrophic factor is essential for neuronal survival in the locus coeruleushippocampal noradrenergic pathway. Neuroscience 124:137-146.

Rajkowska G, Miguel-Hidalgo JJ (2007) Gliogenesis and glial pathology in depression. CNS Neurol Disord Drug Targets 6:219-233.

Rintala J, Seemann R, Chandrasekaran K, Rosenberger TA, Chang L, Contreras MA, Contreras MA, Rapoport SI, Chang MC (1999) 85 kDa cytosolic phospholipase A2 is a target for chronic lithium in rat brain. Neuroreport 10:3887-3890.

Rosenberger TA, Villacreses NE, Hovda JT, Bosetti F, Weerasinghe G, Wine RN, Harry GJ, Rapoport SI (2004) Rat brain arachidonic acid metabolism is increased by a 6-day intracerebral ventricular infusion of bacterial lipopolysaccharide. J Neurochem 88:1168-1178.

Schmidt HD, Duman RS (2007) The role of neurotrophic factors in adult hippocampal neurogenesis, antidepressant treatments and animal models of depressive-like behavior. Behav Pharmacol 18:391-418.

Schulte-Herbrüggen O, Chourbaji S, Müller H, Danker-Hopfe H, Brandwein C, Gass P, Hellweg R (2006) Differential regulation of nerve growth factor and brain-derived neurotrophic factor in a mouse model of learned helplessness. Exp Neurol 202:404-409.

Shi B, Rabin SJ, Brandoli C, Mocchetti I (1998) Dexamethasone induces hypertrophy of developing medial septum cholinergic neurons: potential role of nerve growth factor. J Neurosci 18:9326-9334.

Song C (2009) Omega-3 fatty acid EPA reduces inflammation and upregulates neurotrophins in a rodent model of inflammatory neurodegeneration. Prostaglandins Leukot Essent Fatty Acids, in press.

Song C, Horrobin D (2004) Omega-3 fatty acid ethyl-eicosapentaenoate, but not soybean oil, attenuates memory impairment induced by central IL-1beta administration. J Lipid Res 45:1112-1121.

Song C, Leonard BE (2005) The olfactory bulbectomised rat as a model of depression. Neurosci Biobehav Rev 29:627-647.

Song C, Lin A, Bonaccorso S, Heide C, Verkerk R, Kenis G, Bosmans E, Scharpe S, Whelan A, Cosyns P, de Jongh R, Maes M (1998) The inflammatory response system and the availability of plasma tryptophan in patients with primary sleep disorders and major depression. J Affect Disord 49:211-219.

Song C, Li X, Leonard BE, Horrobin DF (2003) Effects of dietary n-3 or n-6 fatty acids on interleukin-1beta-induced anxiety, stress, and inflammatory responses in rats. J Lipid Res 44:1984-1991.

Song C, Leonard BE, Horrobin DF (2004) Dietary ethyl-eicosapentaenoic acid but not soybean oil reverses central interleukin-1-induced changes in behavior, corticosterone and immune response in rats. Stress 7:43-54.

Song C, Li X, Kang Z, Kadotomi Y (2007) Omega-3 fatty acid ethyleicosapentaenoate attenuates IL-1beta-induced changes in dopamine and metabolites in the shell of the nucleus accumbens: involved with PLA2 activity and corticosterone secretion. Neuropsychopharmacology 32:736-744.

Song C, Taepavarapruk P, Zhang Y (2008) Acute and chronic IL- $1 \beta$ administrations differentially modulate learning and memory, acetylcholine efflux and neurotrophin expressions in the hippocampus: possible mechanisms involved in neuroprotection and neurodegeneration. Brain Behav Immun 22:S41-S42. 
Stampachiacchiere B, Aloe L (2005) Differential modulatory effect of NGF on MHC class I and class II expression in spinal cord cells of EAE rats. J Neuroimmunol 169:20-30.

Strijbos PJ, Rothwell NJ (1995) Interleukin- $\beta$ attenuates excitatory amino acid-induced neurodegeneration in vitro: involvement of nerve growth factor. J Neurosci 15:3468-3474.

van Riezen H, Leonard BE (1990) Effects of psychotropic drugs on the behavior and neurochemistry of olfactory bulbectomized rats. Pharmacol Ther 47:21-34.

von Richthofen S, Lang UE, Hellweg R (2003) Effects of different kinds of acute stress on nerve growth factor content in rat brain. Brain Res 987:207-213.

Wichers MC, Koek GH, Robaeys G, Verkerk R, Scharpé S, Maes M (2005) IDO and interferon-alpha-induced depressive symptoms: a shift in hypothesis from tryptophan depletion to neurotoxicity. Mol Psychiatry 10:538-544.
Wong K, Sharma A, Awasthi S, Matlock EF, Rogers L, Van Lint C, Skiest DJ, Burns DK, Harrod R (2005) HIV-1 Tat interactions with p300 and PCAF transcriptional coactivators inhibit histone acetylation and neurotrophin signaling through CREB. J Biol Chem 280:9390-9399.

Xiao Y, Li X (1999) Polyunsaturated fatty acids modify mouse hippocampal neuronal excitability during excitotoxic or convulsant stimulation. Brain Res 846:112-121.

Yeh YY, Whitelock KA, Yeh SM, Lien EL (1999) Dietary supplementation with arachidonic and docosahexaenoic acids has no effect on pulmonary surfactant in artificially reared infant rats. Lipids 34:483-488.

Yehuda S, Rabinovitz S, Mostofsky DI (2005) Essential fatty acids and the brain: from infancy to aging. Neurobiol Aging 26:98-102.

Zhu G, Okada M, Yoshida S, Mori F, Ueno S, Wakabayashi K, Kaneko S (2006) Effects of interleukin-1beta on hippocampal glutamate and GABA releases associated with $\mathrm{Ca} 2+$-induced $\mathrm{Ca} 2+$ releasing systems. Epilepsy Res 71:107-116. 